\title{
Monaural localization following exposure to different segments of acoustic space
}

\author{
ALAN D. MUSICANT and ROBERT A. BUTLER \\ Departments of Behavioral Science (Biopsychology) and Surgery (Otolaryngology) \\ University of Chicago, Chicago, Illinois
}

\begin{abstract}
Four groups of eight monaural listeners received practice on locating sounds coming from different segments of the horizontal plane prior to a test in which all sounds originated within the same region. An additional eight monaural listeners were given the final localization test without the pretest practice. Knowledge of results was withheld. The main finding was that positive transfer of training was not equally apparent for all groups. That group for which the pretest and test involved the same ear and the same azimuthal positions of loudspeakers performed best. Practice in locating rearwardly positioned sounds did not benefit the localization of frontally positioned sounds even when the same ear was functioning in both situations. Experience in locating sounds from all segments of the horizontal plane appears to be required in order to build up an adequate internal representation of the acoustic surrounds.
\end{abstract}

Practice and its subsequent effect on later performance has been of central interest to psychologists for many years; the literature is replete with studies on transfer of training. In psychophysics, however, the role of practice has been incidental to the main concern of investigators. Subjects are given practice in order to reduce response variability so that the influence of the independent variable can become more clearly detected. In an earlier paper (Musicant \& Butler, 1980), we expressed interest in the possibility alluded to by Plenge (1974) that each time we enter a different acoustic environment, we immediately reintegrate the multifaceted cued for sound localization. A few seconds of "practice" may have an enormous salutary effect on orienting to a new sound field. To find out whether this idea was credible, we restricted one group of listeners' exposure to a sound-treated room by presenting only $2 \mathrm{sec}$ of sound once a day for 4 or 5 days a week. This continued until 60 observations had been gathered. The sounds originated from one of six loudspeakers, and the listeners were requested to locate them monaurally. Localization performance of these subjects was significantly inferior to that of subjects who received one session of massed trials (60 presentations) prior to being placed on the one-trial-a-session regimen. Given that a modicum of sound localization experience (the pretest) had a positive effect on subsequent performance (the test), one question immediately arises: How closely must the conditions of the pretest match those of the test? Conceivably, merely

This work was supported by U.S. Public Health Service Grant NS-11154-05. Reprint requests should be directed to R.A.B., Department of Behavioral Science, University of Chicago, Chicago, Illinois 60637. hearing sounds from one segment of the new acoustic environment would suffice to form an internal representation of that entire space. This internal "map" would then be used as a comparator for locating subsequent sounds originating from any segment of that specific environment. Alternatively, only that segment of auditory space to which the listener has been exposed may be represented internally. If the latter hypothesis is correct, then listeners should be able to locate sounds from a previously experienced segment of space more proficiently than could listeners whose pretest experience consisted of exposure to a different segment of space. We designed an experiment to test this idea.

\section{METHOD}

\section{Subjects}

Forty persons whose hearing thresholds were within $10 \mathrm{~dB}$ of audiometric zero (ISO, Davis \& Krantz, 1964) participated. All were within the age range of 20 to 30 years, and all were naive with respect to hearing experiments. None had previously entered the room in which the study was to be conducted.

Stimuli were generated, shaped, and controlled by the GrasonStadler 1200 Modular Programming System. They originated from a noise generator, then were routed to a cascaded pair of electronic filters (Spencer-Kennedy Laboratories, Model 302) that could be set to provide a $36-\mathrm{dB} /$ octave rejection slope. The signals were next fed to an electronic switch and, upon gating, were amplified (Crown amplifier, Model D60) to be delivered ultimately to 1 of 13 loudspeakers (KLH, 4 in. diam) arranged in an arc approximately $5 \mathrm{ft}$ from the listener. The loudspeakers, separated from one another by $15 \mathrm{deg}$ and numbered consecutively from 1 through 13, extended along a 180-deg arc (see Figure 1). By facing listeners toward Loudspeaker 1, the arc formed a hemisphere left of the midline (180-360 deg); by facing listeners toward Loudspeaker 13, the arc formed a hemisphere right of midline (180-0 deg).
} 


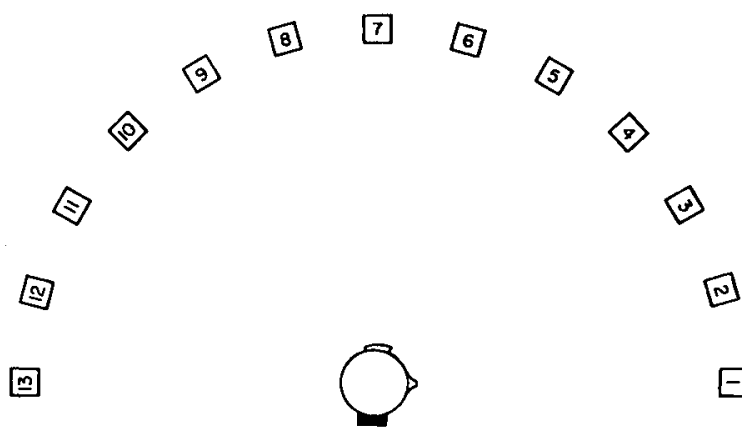

Figure 1. Diagram of loudspeaker position and number relative to the listener's position.

\section{Stimuli}

The sounds consisted of a train of five noise bursts, either broadband or $3.0-\mathrm{kHz}$ high-pass noise. Each burst was $30 \mathrm{msec}$ in duration with a $10-\mathrm{msec}$ rise-fall time. Interpulse interval was 300 msec. Noise bursts were presented to the left or right ear.' Stimuli were presented at approximately $20 \mathrm{~dB} \mathrm{SL} .^{2}$

\section{Pretest Procedure}

The $\mathbf{4 0}$ subjects were assigned randomly to five groups. Four subjects in each group were required to locate broadband noise, four were required to locate $3.0-\mathrm{kHz}$ high-pass noise. Only four of the five groups, however, participated in the pretest. Those that did were presented stimuli from a given set of 6 loudspeakers, although all 13 loudspeakers were available for localization responses. Group $A$ subjects, listening with the left ear, were presented sounds originating from loudspeakers placed at 255 , $270,285,300,315$, and 330 deg azimuth. Group B subjects, also listening with the left ear, were given sounds from the loudspeakers placed at $255,240,225,210,195$, and $180 \mathrm{deg}$. Group C subjects, right-ear listeners, were given sounds from loudspeakers placed at $30,45,60,75,90$, and 105 deg. Group D subjects, again right-ear listeners, were presented sounds from loudspeakers placed at 105, 120,135, 150, 165, and 180 deg azimuth. Subjects in the final group, Group E, were deprived of pretest experience.

Table 1

Summary of Experimental Conditions

\begin{tabular}{|c|c|c|c|}
\hline Group & Stimulus & $\begin{array}{c}\text { Open } \\
\text { Ear }\end{array}$ & $\begin{array}{c}\text { Azimuth of } \\
\text { Stimuli* }\end{array}$ \\
\hline \multicolumn{4}{|c|}{ Pretest (Massed Trials) } \\
\hline $\mathbf{A}$ & $\begin{array}{l}\text { Broadband Noise } \\
\text { 3-kHz High Pass }\end{array}$ & $\begin{array}{l}\mathbf{L} \\
\mathbf{L}\end{array}$ & $\begin{array}{l}255-330 \\
255-330\end{array}$ \\
\hline B & $\begin{array}{l}\text { Broadband Noise } \\
3-\mathrm{kHz} \text { High Pass }\end{array}$ & $\begin{array}{l}\mathbf{L} \\
\mathbf{L}\end{array}$ & $\begin{array}{l}180-255 \\
180-255\end{array}$ \\
\hline $\mathrm{C}$ & $\begin{array}{l}\text { Broadband Noise } \\
3 \mathrm{kHz} \text { High Pass }\end{array}$ & $\begin{array}{l}\mathbf{R} \\
\mathbf{R}\end{array}$ & $\begin{array}{l}30-105 \\
30-105\end{array}$ \\
\hline D & $\begin{array}{l}\text { Broadband Noise } \\
3+\mathrm{kHz} \text { High Pass }\end{array}$ & $\begin{array}{l}\mathbf{R} \\
\mathbf{R}\end{array}$ & $\begin{array}{l}105-180 \\
105-180\end{array}$ \\
\hline $\mathbf{E}$ & None & & \\
\hline \multicolumn{4}{|c|}{ Test (One Trial per Day) } \\
\hline A-E & $\begin{array}{l}\text { Broadband Noise } \\
\text { 3-kHz High Pass }\end{array}$ & $\mathbf{L}$ & $\begin{array}{l}255-330 \\
255-330\end{array}$ \\
\hline \multicolumn{4}{|c|}{ Post test (Massed Trials) } \\
\hline A-E & $\begin{array}{l}\text { Broadband Noise } \\
3 \mathrm{kHz} \text { High Pass }\end{array}$ & $\begin{array}{l}\mathbf{L} \\
\mathbf{L}\end{array}$ & $\begin{array}{l}255-330 \\
255-330\end{array}$ \\
\hline
\end{tabular}

*In degrees.
We established the monaural left-ear listening condition by facing the subject toward Loudspeaker 1; the monaural right-ear listening condition was achieved by facing the subject toward Loudspeaker 13.

The subjects were given a diagram of the loudspeaker arrangement, shown in Figure 1, and were instructed to enter the room, remain silent, and determine for themselves that the information provided by the diagram corresponded to the actual physical placement of the loudspeakers. Next, the listener occupied a chair that was oriented so that his/her open (unoccluded) ear faced the center of the loudspeaker array. $A$ headrest and eye-fixation point, positioned at $\mathbf{0}$ deg azimuth relative to the subject's orientation, fostered compliance with instructions not to move his/her head or eyes from straight-ahead while the stimuli were being delivered. Then the pretest began. Sixty localization trials were presented, with a trial defined as the presentation of a single train of five pulses. Each loudspeaker within the selected arc was activated 10 times, and within a six-trial set, it was activated once. Loudspeaker presentation order differed for every subject in an irregular manner. Listeners indicated the apparent source of the sound by writing the corresponding loudspeaker number on an answer sheet.

\section{Test Procedure}

On the day following the 60 massed trials, a one-trial-a-session regimen began and continued for 24 sessions. Typically, the subjects were tested four or five times a week. All listened with the left ear, the right being occluded. All received sounds emanating from the same set of loudspeakers-those six positioned at 255 through $330 \mathrm{deg}$ azimuth. A session was conducted in the following manner: After the subject was seated, the room lights were quickly switched off and on again, which signaled that a single train of noise bursts would occur after about $1 \mathrm{sec}$. Listeners selected among the 13 loudspeakers the one they judged to be the sound's source. They wrote its number on an answer sheet and then immediately left the room, to return after a day or two. No feedback was provided at any time.

\section{Posttest Procedure}

Sixty massed trials followed the one-trial-a-session test. The sounds originated from the same loudspeakers that were activated during the test, that is, the ones stationed at $255,270,285,300$, 315, and 330 deg. Again, listeners wrote their choices of the loudspeakers responsible for the sounds on an answer sheet.

Table 1 outlines the experimental conditions which characterized the pretest, test, and posttest. Note that we did not activate loudspeakers stationed on the midline or $15 \mathrm{deg}$ on either side of the midline. The reason for this was that listeners, when made suddenly monaural, displace sounds from the front toward the side of the functioning ear (Bauer, Matuzsa, Blackmer, \& Glucksburg, 1966; Butler \& Planert, 1976). Given the limited amount of localization experience that we had planned for our listeners, we chose to investigate localization performances from that segment of the horizontal plane in which other listeners had previously shown measurable improvement after a relatively brief exposure to the stimuli, which turns out to be the segment bordered by 255 and $330 \mathrm{deg}$ azimuth when listening with the left ear (Musicant \& Butler, 1980).

Localization proficiency was evaluated in terms of error score (ES) defined as the absolute difference in azimuth between the loudspeaker activated on a given trial and that chosen as the source of the sound.

\section{RESULTS}

A split-plot ANOVA was carried out to test for significant effects attributable to differences (1) among Groups A through D, and extended through Group E 


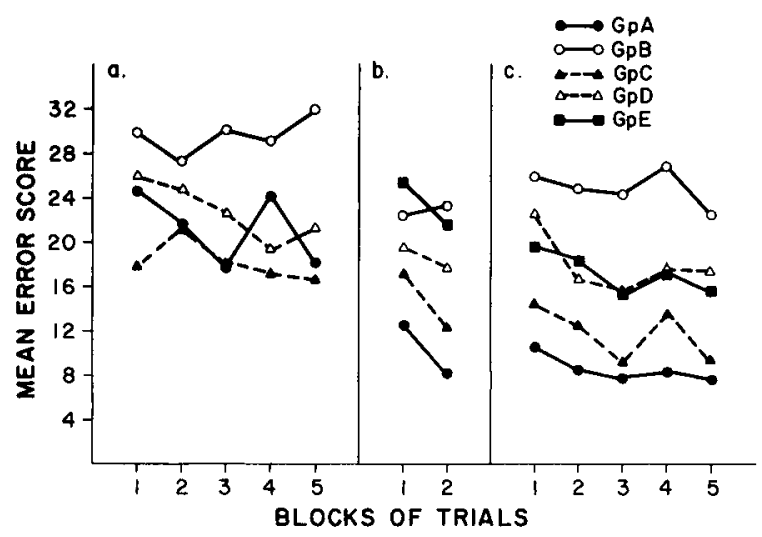

Figure 2. Mean error score per listener as a function of trial block.

when applicable, (2) between stimulus compositions, (3) among loudspeaker positions, and (4) among consecutive blocks of trials. When differences for the main effects occurred, a Newman-Keuls post hoc analysis was conducted to probe more directly the sources of the significance.

\section{Pretest Performance}

No significant differences among or between conditions for any of the main factors were found. Figure 2a plots mean ES as a function of consecutive blocks of 12 trials for Groups A through D. Neither improvement in locating sounds as the session progressed nor differences in performance among groups were clearly in evidence.

\section{Test Performance}

For these localization trials, robust differences among conditions did emerge from the analysis. Those among the groups were significant beyond the $2 \%$ level of confidence, those among the loudspeaker positions, beyond the $1 \%$ level, and those among blocks of trials, beyond the $.2 \%$ level. First, an examination of group differences: The mean ES was least for Group A, the group that located sounds in the same arc segment on the pretest (255-330 deg). Then, in terms of increasing ES came Groups C, D, and lastly, Groups B and E. The ESs of the latter two groups were the most similar. These data are illustrated in Figure 2b. When applying the NewmanKeuls test to these results, we found that while Groups $A$ and $C$ performed better than the rest, only the ESs for Group A differed significantly from those of Groups B and E, the least proficient performers (see Table 2a for the results of the Newman-Keuls test).

Second, we examined more closely the contributors to the main effect of loudspeaker position. What happened overall was that listeners performed worst, that is, ESs were greater, when stimuli originated from the frontal sector of the arc. Specifically, ESs for the sounds coming from $255 \mathrm{deg}$ azimuth differed significantly from those recorded for sounds coming from 300,315 , and $330 \mathrm{deg}$; sounds from $270 \mathrm{deg}$ differed significantly from those coming from 300 , 315 , and $330 \mathrm{deg}$; sounds from 285,300 , and $315 \mathrm{deg}$ differed significantly from those coming from $330 \mathrm{deg}$ (see Table 2b). The significant interaction between groups and loudspeaker position $(p<.003)$ was informative, for it is here that we discover the basis for the superior performance of Groups $A$ and $C$. The Newman-Keuls test revealed that Groups $A$ and $C$ located sounds from all loudspeaker positions with approximately equal proficiency; that is, no significant differences showed up for ES associated with loudspeaker position. On the other hand, Groups B, $D$, and $E$ uniformly showed higher ESs when the sounds came from $330 \mathrm{deg}$ and exhibited somewhat elevated ESs for sounds emanating from 315 and 300 deg azimuth. Table $2 \mathrm{c}$ summarizes these results. In addition, Figure 3 provides a plot of mean ES per 24 trials as a function of loudspeaker position-a plot which clearly differentiates between the performance of Groups $A$ and $C$ and that of the other groups. Third, with respect to blocks of trials, ES was significantly different (less) on the second block. Since no other factors interacted significantly with blocks of trials, no further analyses of these data were performed.

\section{Posttest Performance}

An ANOVA indicated that differences among groups were significant beyond the $2 \%$ level, loudspeaker position beyond the $.1 \%$ level, and among

Table 2

Newman-Keuls Post Hoc Analysis of Test Data

\begin{tabular}{|c|c|c|c|c|c|c|c|c|c|c|}
\hline \multicolumn{3}{|c|}{ (a) Group Differences } & \multicolumn{4}{|c|}{ (b) Loudspeaker Differences } & \multicolumn{4}{|c|}{ Groups B, D, and $\mathrm{E}^{1}$} \\
\hline & B & $\mathrm{E}$ & & 300 & 315 & 330 & & 300 & 315 & 330 \\
\hline $\mathbf{A}$ & $*$ & $*$ & $\begin{array}{l}255 \\
270 \\
285 \\
300 \\
315\end{array}$ & $\begin{array}{l}* \\
*\end{array}$ & $\begin{array}{l}* \\
*\end{array}$ & $\begin{array}{l}* * \\
* * \\
* * \\
* * \\
* *\end{array}$ & $\begin{array}{l}255 \\
270 \\
285 \\
300 \\
315\end{array}$ & $* 2$ & $\begin{array}{l}*(*)^{3} \\
*(*)^{3}\end{array}$ & $\begin{array}{l}* * \\
* * \\
* * \\
*(*)^{4} \\
*(*)^{4}\end{array}$ \\
\hline
\end{tabular}

${ }^{*} p<.05 . \quad{ }^{* *} p<.01 . \quad{ }^{1}$ Groups $A$ and $C$ showed no significant differences across loudspeakers. $\quad{ }^{2}$ Groups $B$ and $D$ only.

${ }^{3}$ Group E only. "Groups $B$ and $E$ only. 


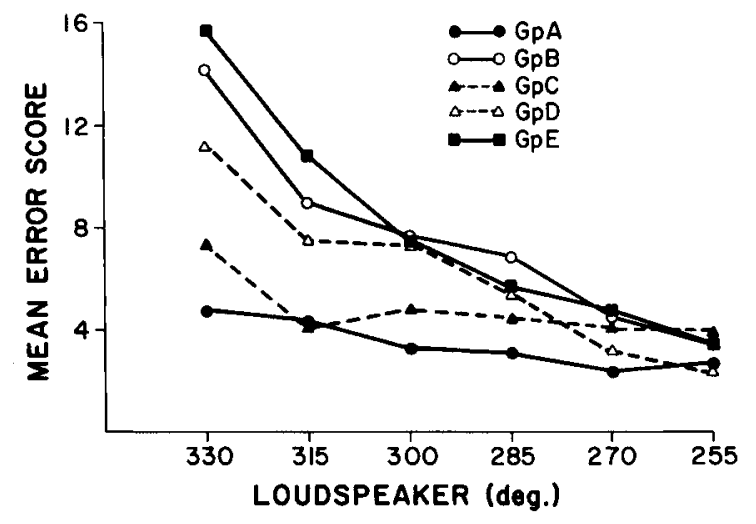

Figure 3. Group $\times$ loudspeaker interaction. Mean error score per listener as a function of loudspeaker position.

blocks of trials beyond the $.1 \%$ level. Again, we called upon the Newman-Keuls test to further elucidate what may have contributed to those main effects. Turning first to group differences, we found that ESs recorded for Group A differed significantly from those recorded for Group B (see Table 3a). With respect to the source of significance for the main effect of loudspeaker position, the Newman-Keuls test indicated that ESs associated with locating sounds emanating from $330 \mathrm{deg}$ azimuth were significantly different (higher) from those recorded for listeners locating stimuli originating from the other azimuthal positions (see Table 3B). In addition, ESs at 315 deg differed significantly from those recorded at $255 \mathrm{deg}$. The significant differences among blocks of trials were attributable, in large part, to the fact that ES was greater on Block 1 than on Blocks 2 through 5. Another contributing factor was an enhancement in ES for Block 4 re Blocks 3 and 5-a finding that is recorded in Table 3c. No significant interactions between or among main effects were in evidence for the posttest performances. We wondered whether all groups would perform more proficiently on the posttest than on the pretest, for by the time the posttests were given, everyone had had considerable exposure to the localization task. Yet, according to the Wilcoxon matched-pairs signed-

Table 3

Newman-Keuls Post Hoc Analy ses of Posttest Data

\begin{tabular}{|c|c|c|c|c|c|c|c|}
\hline \multicolumn{2}{|c|}{$\begin{array}{c}\text { Group } \\
\text { Differences }\end{array}$} & \multicolumn{3}{|c|}{$\begin{array}{c}\text { Loudspeaker } \\
\text { Differences }\end{array}$} & \multicolumn{3}{|c|}{$\begin{array}{c}\text { Block } \\
\text { Differences }\end{array}$} \\
\hline & B & & 315 & 330 & & 4 & 1 \\
\hline $\mathbf{A}$ & $*$ & $\begin{array}{l}255 \\
270 \\
285 \\
300 \\
315\end{array}$ & * & $\begin{array}{l}* \\
* \\
* \\
* \\
*\end{array}$ & $\begin{array}{l}5 \\
3 \\
2 \\
4\end{array}$ & $\begin{array}{l}* \\
*\end{array}$ & $\begin{array}{l}* \\
* \\
* \\
*\end{array}$ \\
\hline
\end{tabular}

${ }^{*} p<.05$. ranks test, only Group A showed a significant reduction in ES $(p<.05)$.

We should mention that differences between stimulus composition were not significant for pretest, test, or posttest performance.

\section{DISCUSSION}

The question that served as the impetus for this study was whether experience in locating sound in one restricted segment of the horizontal plane would benefit subjects when they were later asked to locate sounds from a different segment. We discovered that the transfer of localization training was reasonably specific. Listeners (Group A) who were presented sounds from the same azimuthal range during both the pretest and test sessions did best. This superior performance cannot be attributed to the fact that the same ear (left) was functioning during both tasks, since Group B, also required to locate sounds with the left ear during the pretest sessions, performed poorly. In fact, its members located at about the same level of competence as did those in Group E, the group receiving no pretest experience. Sounds delivered to Group B, however, originated in the rear rather than in the front sector of the horizontal plane, and this difference may have been responsible for the absence of the practice effect. It is of interest to note that the group that performed nearly as well as Group A, viz, Group C, was also presented sounds from the frontal sector during the pretest. Since Group C's pretest experience involved listening with the right ear, we suggest that front vs. rear rather than left ear vs. right ear may have been the important distinction in the pretest experience. It appears that practice in locating frontally stationed sounds aided subsequent performance when the stimuli originated from the frontal sector. Our experimental design did not allow us to determine whether the obverse would hold. We suspect it would.

A portion of these data essentially confirms the results of our earlier study (Musicant \& Butler, 1980). We reported then that a listening group that received 60 massed trials in locating sound monaurally performed more accurately when, later, the stimuli were presented from the same azimuthal segment. The reference group in this case consisted of listeners who had not had pretest training. Groups $A$ and $E$ in the present study correspond to the two groups just mentioned, and differences in performance match those found in the original experiment. Moreover, subjects in the current study, like those in the previous one, exhibited significant improvement during the test, an event consisting of just one trial a session. This finding, which we now consider to be well established, poses problems. To elucidate: We decided to probe for the effects of pretest experience by presenting 
only one trial a session during the test. We assumed that by severely curtailing the opportunity for further practice throughout the test, we would not destroy what we wanted to study, viz., the effect of the original auditory exposure to the environment on localization performance. But the remarkable result was that listeners did improve during the test despite so little additional practice. If a person builds up a cognitive map of the acoustic space by comparing successive sounds emanating from various locations, a reasonable hypothesis, it is difficult to understand how improvement in localization can take place when the subjects are given no more than about $15 \mathrm{sec}$ of practice a week in the localization task. These data suggest that brief exposure to an acoustic surround has an immense positive effect on the ability to detect the direction of a sound. Presumably, we are dealing, here, with the initial formation of an internal representation of auditory space. It is a difference between (1) not knowing where the sound is originating and (2) judging it to be emanating from a somewhat restricted segment of space. With additional practice, that segment becomes further, and much more finely, differentiated. It is this latter stage of improvement which we normally associate with the effects of practice.

The significant interaction (groups $\times$ loudspeaker position), graphically illustrated in Figure 3, uncovers one of the benefits derived from pretest experience. To wit, on the test trials, sounds emanating from 330 and $315 \mathrm{deg}$ azimuth were located more accurately by Groups $\mathrm{A}$ and $\mathrm{C}$, the groups to which sounds from a frontal sector were presented during the pretest. As mentioned earlier, there exists a penchant to displace sounds toward the open ear when locating monaurally. ${ }^{3}$ Apparently, members of Groups $A$ and $C$ learned to compensate for this tendency during those 60 massed trials presented on the previous day.

The finding that performance on localizing $3.0-\mathrm{kHz}$ high-pass and broadband noise did not differ from one another is consistent with previous data on monaural localization (Belendiuk \& Butler, 1977). Cues for locating sounds monaurally are primarily spectral and are mainly provided by the pinna. Due to the pinna's relatively small size, it interacts only with sounds of shorter wavelengths; hence, for localization purposes, the lower frequencies are superfluous.

Our experimental conditions for the pretest were, of course, highly contrived. It is unlikely that one's introduction to a new acoustic environment would entail this pattern of acoustic stimulation. Even if the sound came from a single source, people would turn their heads about, thereby experiencing successively sounds coming from a large segment of the hori- zontal plane. They would, in effect, obtain a kaleidoscopic view of the available acoustic cues-temporal differences, intensity differences, and spectral differences. So the hypothesis that we may reintegrate cues for localization each time we enter a different environment continues to warrant attention. Our work, however, indicates that not all patterns of acoustic experience contribute equally in improving the subsequent localization of sound whose genesis is restricted to a specific segment of the horizontal plane. It looks as if that particular acoustic space must be previously experienced before sounds from that region can be located proficiently.

\section{REFERENCES}

Bauer, R. W., Matuzsa, J. L., Blackmer, R. F., \& Glucksburg, S. Noise localization after unilateral attenuation. Journal of the Acoustical Society of America, 1966, 40, 441-444.

Belendiuk, K., \& Butler, R. A. Monaural localization of lowpass noise bands in the horizontal plane. Journal of the Acoustical Society of America, 1975, 58, 701-705.

Belendiuk, K., \& Butler, R. A. Spectral cues which influence monaural localization in the horizontal plane. Perception \& Psychophysics, 1977, 22, 353-358.

Butler, R. A., \& Planert, N. The influence of stimulus bandwidth on localization of sound in space. Perception \& Psychophysics, 1976, 19, 103-108.

Davis, H., \& Kranz, F. W. The international standard reference zero for pure tone audiometers and its relation to the evaluation of impairment of hearing. Journal of Speech and Hearing Research, 1964, 7, 7-16.

Musicant, A. D., \& Butrer, R. A. Monaural localization: An analysis of practice effects. Perception \& Psychophysics, 1980, 28, 236-240.

Plenge, F. On the difference between localization and lateralization. Journal of the Acoustical Society of America, 1974, 56, 944-951.

\section{NOTES}

1. Subjects were rendered monaural by placing a mine safety appliance (MSA) ear defender in the appropriate ear and then covering that ear with an MSA muff. This procedure has been found to effectively elevate thresholds to broadband noise by approximately $28 \mathrm{~dB}$ (Belendiuk \& Butler, 1975).

2. The loudness level was based on threshold data from five observers who did not take part in the study. Their hearing acuity was also within $10 \mathrm{~dB}$ of audiometric zero for the frequencies .125 through $8.0 \mathrm{kHz}$. Thresholds for left and right ears to broadband and $3.0-\mathrm{kHz}$ high-pass noise bursts generated by each of the 13 loudspeakers were obtained. The averages for each stimulus and loudspeaker position were calculated and used as the zero references for the sensation levels to be used in the study. Had we taken thresholds of our subjects in order to arrive at $20 \mathrm{~dB} \mathrm{SL}$ for the localization trials, we would have given them additional experience in the acoustic environment. This we wished to avoid.

3. Groups B and D, to whom sounds were presented from behind them during the pretest session, also displaced sound toward the open ear, but no compensation for this was apparent on the test.

(Manuscript received August 13, 1981; revision accepted for publication December 17, 1981.) 